\title{
Strategic Teaching of Strategic Thinking
}

\author{
Maria L. Nathan \\ School of Business and Economics, Lynchburg College, United States
}

Copyright $(2015$ by authors, all rights reserved. Authors agree that this article remains permanently open access under the terms of the Creative Commons Attribution License 4.0 International License

\begin{abstract}
This paper will explore strategic thinking as a threshold concept and key integrative framework within the management discipline. Threshold-concept primed applications with which to enhance both the teaching and learning of this concept will then be offered as means to also facilitate transfer of learning to other contexts, including the workplace setting. The theory of threshold concepts [cf: 1, 44], actionable and rich in explanatory merit, underpins this research and ultimately gives definition to a highly strategic approach to teaching strategic thinking.
\end{abstract}

Keywords Strategic Thinking, Teaching Strategic Thinking, Threshold Concept Theory

\section{Introduction}

Threshold concept theory focuses an analytic lens upon key concepts that are critical to the command of a discipline [1]. The opportunity cost in economics, depreciation in accounting, and self-leadership in management are just several business-related examples (cf: [2-4].

Instructors who puzzle over student indifference, perfunctory responses, surface learning, or rapid forgetting, find that threshold concept theory provides a highly enlightened approach to understanding student failure to learn that can exert a profound effect upon how a course is taught [1]. For example, the instructor who has taught a leadership course for many years may find that the theory of self-leadership irreversibly changes the way the course must be taught. If one must first lead and manage the self effectively before embarking on the task of leading and managing others [5], then a substantial shift in how the course is taught may be compelled.

In general, learning that is enlightened has among the following characteristics: Focus shifts from very other-directed to student-self-directed; motivation is shifted from extrinsic to intrinsic; student cognition shifts from cool and dispassionate to hot with zest and momentum; the student is not learning about but learning to do; focus centers not upon pieces of the puzzle, but to whole-game learning. Finally, such learning shifts from problem solving to problem finding and problem defining [6]. Threshold concept primed teaching promotes just such enlightened learning.

One threshold concept that is central to the field of management is strategic thinking. Once truly learned, strategic thinking holds great promise as among the most useful and practical life and career-changing management concept for the business school student. Strategic thinking involves "promoting unorthodox perspectives, challenging the obvious, and fostering divergent thinking and creative solutions [7]. It involves premeditation, anticipation of the reaction of others, and the design of coordinated action [8]. The strategic thinker continually seeks to create connections between people, ideas, and plans that others may fail to see, then seeks to advance interests at these particular connection points [9].

Ironically, although strategic thinking is usually only briefly treated in an introduction to management course, and then again in a capstone strategy and policy course, students may graduate not having fully integrated strategic thinking into their business nor their own personal thinking. This critical concept may not have been used to its fuller integrative, boundary defining, and personal transformation potential. Troublesome items such as how levels of the organization unite around a particular strategy, or exactly how organizational vision, mission, objectives, and strategy actually come together to create financial results may lie fragmented and unused by the student - both conceptually and in practice. It is argued here that recognizing strategic thinking as a threshold concept permits the use of a powerful magnifying lens that focuses and clarifies study for deeper reaching, meaningful, and productive teaching, learning, and living. The significance of the management function as a critical core of the effective and competitively competent organization is underscored as the strategic thinking process comes to be more fully and satisfactorily understood.

This paper is structured as follows: Strategic thinking as a threshold concept is first discussed, then means by which threshold concept theory opens the door to both more effective learning and teaching of strategic thinking is explored. Finally, future directions for research into teaching strategic thinking as a threshold concept are offered. The purposes of this paper are to offer a strategic and 
theory-guided lens with which instructors may refresh and recharge thinking about how strategic thinking is taught in the management education curriculum, and how students may more fully apprehend the big picture of how strategic thinking relates to management, organizations, and life in general. This paper seeks to offer strategic educational applications that can compel unforgettable personal and business insights for learners.

\section{Strategic Thinking as a Threshold Concept}

The term strategic thinking has tended to be used to denote all kinds of thinking about strategy rather than a particular mode of thinking [10]. Alternatively, strategic thinking is a more precise exercise that holds certain characteristics. It is: (1) systemic in character - offering a mental model of a complete end-to-end system of value creation and interdependencies within. In this way, the thinker surfaces, tests, and improves internal pictures of how the world works; (2) intention- driven -- offering a unique point of view about where an organization is heading, and helping to focus attention and resist distraction; (3) intelligently opportunistic, allowing for the emergence of new, creative, and adaptive strategies; (4) time-expansive, integrating the past, today's reality, and the future. Finally, (5) strategic thinking is hypothesis-driven, developing tenable hypotheses and testing them efficiently. Thus, it can be said that strategic thinking views the big picture, reaches into analytic depths, and expansively integrates past, present, and future [11-12].

Strategic thinking as a threshold concept is central and critical to an understanding of management in general. A set of key threshold concept properties enumerated by Meyer, Land, and Smith [13] and others greatly enhances the utility of the concept of strategic thinking for the instructor. Strategic thinking: (1) involves forms of "troublesome knowledge" and other concepts that may appear illogical, unfamiliar, or even alien [14-15]; (2) is an integrative concept that serves to create new connections and patterns for the student of organizations, (3) results in change in understanding that is usually not reversible; (4) proves transformational, changing the way the thinker thinks and acts [16], (5) marks the boundaries of the management discipline and strategic management sub-discipline. Exploration of these properties as applied to strategic thinking serves to heighten educator awareness of a fuller potential for learner enlightenment.

(1) Troublesome Knowledge: Strategic thinking is laden with difficulties and paradoxically complex hot spots for the management student. Troublesome is the fact that brilliant strategic thinking may not actually translate into brilliant strategy implementation; competitive advantage that is sustained may not yield superior financial returns; team strategic activities may not necessarily reflect clear-sighted strategic thinking, and evaluation of organizational performance will be sharply limited by what was measured in the process.

Outside-of-the-box thinking, scenario planning, and alternate views of a strategic predicament - are all mainstays of the strategic thinking process that may be quite difficult to learn. Alien to the student might be the methods that are fundamental to strategic thinking. It might appear illogical to the student that a case's key decision maker chose a path that seems wild and haphazard (yet cutting edge and boldly brilliant) - until the student too sees the realistic choices more clearly through an edifying strategic thinking process.

(2) Integrative of Connections and Patterns: Strategic thinking is penetratingly integrative as a stream of decisions cohere in the formation of an organization's actual strategy. Several difficult integrations for students to make are vertical-corporate, business-unit, functional, and operational levels of the organization, and horizontally-across functional areas of organizational activity such as marketing, research and development, and information systems. At the heart of both vertical and horizontal levels is the strategic thinking process from which flows the strategic plan of action. Strategic thinking is a core process that knits together diverse levels and functions. Strategic thinking integrates thinking, plans, and the organizational strategic plan itself.

There are many other potentially powerful integrative devices born of strategic thinking. The SWOT Analysis integrates organization strengths/weaknesses and external opportunities and threats. An individual within the organization who seeks to be integrative might conduct a personal SWOT and then integrate it with the organizational SWOT as a means to find professional strengths that might uniquely serve the organization or significant weaknesses that might trip him or her up in the pursuit of career gains.

(3) Non-Reversibility: Non-reversible understanding of concepts that are truly learned well and deeply is an ultimate hope of the strategy instructor. As an example, assumption surfacing frequently proves troublesome not just to the student trying to learn how to use this more difficult to understand strategic tool, but for the instructor as well. How do you get to that rock-solid foundation in a strategic thinking exercise so that there is no troublesome assumption left that could potentially destroy a project? Once students understand how assumption surfacing works, they are unlikely to forget it.

(4) Transformative: 'Transformative learning is not independent of content, context, or a discipline. It's not an 'add on' to a course, but a way of making learning of knowledge in a discipline in a way that students don't passively accept and believe what they are told or what they read, but rather engage in debate, discussion, and critical questioning of the context. Promoting transformative learning is a part of 'covering' content' [17-18]. "Transformative learning involves experiencing a deep, structural shift in the basic premises of thought, feelings, and actions. It is a shift of consciousness that dramatically and irreversibly alters our way of being in the world" [19:11].

The transformational qualities of true strategic thinking 
are unmistakable. Unfocused, the student of strategic thinking may wander through, for example, assumption surfacing, to Porter's Five Forces Analysis, to the SWOT Analysis, and on to a general environmental analysis such as the PESTEL (political, economic, societal, technological, environmental, legal facets of the general environment) and not fully understand these tools and how they are integrally related - either conceptually or in regards to a real organizational story that might have just been read in Fortune magazine. Once the student comes to understand that $\mathrm{s} /$ he has just conducted a thorough, inside/outside, multi-level, and systemic exercise that is essentially an extended session of strategic thinking, s/he then crosses a threshold to an identity as a strategic thinker. A student may come to more fully understand the meaning of "strategic" thinking and now recognize how this may create an entirely different worldview and corresponding way of life.

Use of virtually all of the basic tools of organizational strategic thinking can be applied to personal self-strategy for life and career. For example, values are at the deepest core of an organization, and are critical to an understanding of how an organization chose a particular path. Similarly, an individual's values are central to an understanding of why $\mathrm{s} / \mathrm{he}$ chose a particular path and made the decisions $\mathrm{s} / \mathrm{he}$ made.

Additionally, an affective shift in values, feelings, and attitudes may co-occur as a student reflects upon past decisions that may have been made while operating in a non-strategic mode. A student, for example, may come to see how a stream of ill-conceived and not particularly strategic exercises has led him to a challenging and life altering crossroads. This student acquires the threshold concepts of strategic thinking and then can extend his use of language in relation to this concept. The student now recognizes that means by which organizational sustainable competitive advantage is acquired may readily transfer to personal career prospecting as well. Dramatically enhanced ability may be the result [1].

(5) Boundary Defining: Finally, the very boundaries of the field of management are more clearly delineated via strategic thinking. How the various functional business disciplines relate to management, how strategic management is distinct from management in general, what makes thinking strategic vs. non-strategic, why every decision should be seen to have a strategic component. These are just a few ways in which the boundaries of the discipline of management are shaped [2], and may serve to enhance an ability to more finely discern new concepts caught in the conceptual spaces shared with border disciplines. Blue Ocean Strategy [20], for example, is just one such concept to be found at the intersection of management and economics disciplines.

The troublesome nature of some threshold concepts may come not from the concepts themselves but from the way the concepts come together to create an underlying game that transforms student understanding at a deeper level [6]. Troublesome and transformative elements may be found in how a field's concepts interact in a process of increasing complexity [21]. Scholars call these threshold conceptions because they bond together aspects of a subject that may seem disparate to a novice [22:54]. Next, applications through which the threshold concept illuminates the teaching of strategic thinking are turned to.

\section{Strategic Teaching of Strategic Thinking}

Instructors try to find student learners' stuck places and resistances [23:2]. Difficulty in understanding strategic thinking may leave the learner in a state of liminality that is a suspended state in which understanding approximates a kind of mimicry or lack of authenticity [1]. Students who become stuck are likely to resort to rote learning. Surface or rote learning has an uncritical focus on what needs to be learned to pass the course without concerns for how the material may sustain in the student repertoire beyond the exam [23].

Framing strategic thinking as a threshold concept richly serves to guide and support its' teaching and learning in many respects. It is itself a strategic effort that offers distinct, useful, and actionable insights. Implications that flow from the recognition of strategic thinking as a threshold concept follow in an exploration of a set of pedagogical applications.

(1) A Curricular Consideration: A threshold concept is as a portal opening up a previously inaccessible way of thinking for the learner. It represents a transformed internal view of a subject matter, subject landscape, or even worldview without which the learner cannot progress.

It might prove useful to place formal exposure to strategic thinking earlier in the curriculum as a meta-cognitive and holistic framework upon which to place what is being learned over time. Otherwise, the level of conceptual fragmentation remains higher and until what is usually the final semester of a student's undergraduate education.

Some schools instead may teach the strategy and policy course at the beginning of the business and/or management curriculum, not as a final capstone. They would do this because students can then see the integrative big picture, focus long term, and have early access to elucidative strategic analyses from the start of their business education, not only at the end. Thus, integration and transformation can begin earlier rather than later since both processes may be protracted over a greater length of time beyond a semester's length $[24,1]$. Threshold concepts need a certain amount of 'soak time' as the learner is immersed into a new world and particular language. Earlier and meaningful treatment of strategic thinking could provide this needed early immersion and opportunity for movement from liminality to fuller comprehension.

Strategic concepts can be troublesome not just cognitively, but also emotionally, attitudinally, bodily, interpersonally, institutionally, and/or socially [25]. This may be just what the instructor seeks as such unsettling opportunities may prompt needed learner initiatives that can lead to desired transformation. 
(2) Strategic Thinking Refreshed and Afresh: Threshold concept theory's application within a discipline requires careful and adroit instructor attention in what can prove to be an invigorating exercise for all. The student-centered instructor is tackling troublesome concepts, teaching multiple models and lenses, challenging beliefs and assumptions, probing learner emotions, and precipitating transformational shifts in learner understanding and identity. The instructor is facilitating student efforts to integrate across levels and see disciplinary boundaries more clearly. The instructor roots out student inauthenticity and rote response in an effort to diagnose and stabilize the student out of potentially lengthy bouts of liminality. Teaching the threshold concept of strategic thinking is itself challenging to the instructor well beyond typical troubles such as class-size constraints, uniform textbook selections across instructors, time issues and more. Thus, the exercise can be optimistically construed as invigorating in ways that may challenge the beliefs, assumptions, values, and mental models of instructors themselves. An ideal might be that each semester the instructor braces him/herself for another strenuous and strategic workout.

(3) Better Strategic Thinkers through Meta-Cognitive Capacity Building: Characteristics of adroit strategic thinkers include: open mindedness, systems thinking, diversity savvy, outside-of-the-box and out of the comfort zone --even-- at times-- outrageous thinking; curiosity and questioning; optimism and confidence in the ability to create a desired future; an ability to readily surface assumptions that underlie thinking; self-awareness of own world views, values, passions, strengths, and weaknesses. The most effective strategic thinkers are also compassionate, generous, and seek to foster the collective good [26] - they strategize with the heart, not just the mind.

The strategic thinker constantly works at improving strategic thinking. Own opinions are constantly questioned; own analyses are regularly questioned as others' criticisms are offered. The strategic thinker reads and surrounds $\mathrm{him} /$ herself with people who think differently and who hold different consulting and academic backgrounds. The strategic thinker's brain and body are recharged regularly. $\mathrm{S} / \mathrm{he}$ seeks out different and diverse environments in an exercise that challenges worldview [27]. In essence, the student is supported in efforts to move the brain from an autopilot's patterned responses and habitual thinking that doesn't work well when uncertainty is dominant to manual steering.

'Genius in truth means little more than the faculty of perceiving in a non habitual way', said William James. The very capacity to think strategically is strengthened as students are trained to develop a global outlook, see larger patterns in the surrounding world, see completely new paths of thinking, create new habits in response to situations, and create new, creative connections.

Strategic thinking is meta-cognitive as it influences self-regulated learning in both the short and long run [28-29]. Thus, the instructor searches for means to assure sustainability of knowledge, insights, and skills so that what the student learned endures beyond the duration of the course and over time. For example, [30] required reflective learning journals within an accounting course to enhance the development of transferable skills in accounting graduates. Journaling enabled students to become aware of and to critically assess both their learning process and the course material presented. To get a student to learn what is metacognitive, it's also helpful to have him/her partner up with other students to discover common difficulties and anxieties.

'The eye altering alters all' [31:228]. There are many other frameworks and other tools that serve to stimulate better strategic thinking in students. For example, Cummings and Wilson's [32] Images of Strategy used many different strategic images to promote more insightful, resourceful, and creative strategic thinking. Krogerus and Tschappeler [33] supplied a fascinating little black book that discusses 50 strategic thinking models, including a system's perspective, stakeholder mapping, value system analysis, the future search conference, intent-focused story writing, scenario building, gap analysis, and the 'making-of' model that focuses upon the need to first understand one's past before determining one's future. If the only tool is a hammer, you tend to see every problem as a nail.

Conceptual change shapes practice [34]. A facility for applying multiple models to strategic projects increases students' intelligent opportunism and constitutes a meta-cognitive mechanism for broad minded and deep reaching strategic thinking.

(4) Strategic Brain Training: Strategic Memory Advanced Reasoning Training (SMART) experts at the Center for Brain Health [35] argued that it is as important to monitor brain fitness as it is physical fitness. Neuroscientists have been studying the development of strategic thinking ability through brain training exercises. They reveal methods by which strategic thinking can be built through exercises in advanced reasoning and innovative problem solving. The frontal lobe of the physical brain itself changes with strategic training [36]. Lumosity, a popular Internet-based brain training organization also uses diverse cognitive exercises such as pattern matching and memory tests, in their training. The strategy instructor can readily access these tests and could embed their use into a course as experimental and experiential exercises that can also offer an opportunity for students to demonstrate brain-training results even over the course of a semester.

(4) The Experiential Exercise and Its Design: Strategists don't just know about but also do strategy. Student strategists take on at least three distinct roles as they learn (Phillips in [7]: active learner, social learner, and creative learner. They construct meaning in dialogue with others, but they must create or recreate knowledge for themselves. It is not enough that they assume an active stance.

Strategic thinking exercises can be challenging, fun, immersive, and highly instructive; students frequently love them. Key ingredients for the strategic thinking exercise that 
is primed as a threshold concept include arousal of emotions such as fear, frustration, hope, and passion--not just logic. Students must also be encouraged to think atypically--in new ways and new paths that introduce strategic twists that may make them feel uncomfortable with their ways of thinking and don't match expectations or reality [37].

Active engagement through experiential exercises such as role-play, action learning, and team dialogues leads to better retention, understanding, and use of knowledge [7]. Team and individual simulations permit the learner to safely experiment to gain insight into cause and effect relationships. In the team simulation students may learn a great deal from their peers; individualized simulations, however, may more readily identify where a student is stuck in their understanding. Extended and active engagements through apprenticeships and internships also invoke the needed experiential exercise that promotes active and deeper reaching learning [37]. Do and then know even better.

(5) Thinking that is Non-Strategic: Some Clues: One strategy blogger offered '29 clues' that someone is not thinking strategically, including that the person wants to limit strategic conversations to top management, has disconnected strategy from day-to-day organizational activities, and experiences discomfort with addressing multiple ideas in search of a solution. Other marks of non-strategy include off-putting of questions from those who are subordinates, unwillingness to question the status quo, and use of a disproportion amount of time on easy problems relative to their ability to produce value for the organization and its customers [38]. A failure of strategic thinking may also be demonstrated when a person registers a lot of discomfort with what is unknown and uncertain in a situation.

Strategic thinking is also diminished by varied blinders such as mental filters and overconfidence; a search for confirming vs. disconfirming evidence, and a dislike for ambiguity and group think [38]. 'Managers who get caught in the trap of overwhelming demands become prisoners of routine. They do not have time to notice opportunities. Their habituated work prevents them from taking the first necessary step toward harnessing willpower: developing the capacity to dress main ideas into existence and transforming it into a concrete existence." [39].

(6) From Classroom Cradle to Work and Life: The challenge is to think strategically all through the strategy capstone course and then beyond the class. The student is challenged to continue to work on brain and mind fitness, strategic thinking, and strategic living -advisedly for a lifetime. The transfer of training from class to life requires that the student fully grasp that strategic thinking is life skill for future application too.

In fact, the smallest employee decision can be put in the context of the organization's broader goals [40] because doing so may provide unique insights into supplier, customer, and competitor needs, wants, and requirements. Thus, there is a strategic element in each decision of each individual working within an organization. An employee can reap rewards by finding and acting upon the strategic facet in his decisions about his relationships with bosses, co-workers, and team-mates; worst enemies and best friends; competitors, suppliers, and others. Acknowledgement of the strategic element helps the employee to understand how to do more of what the organization most needs and wants in a way that makes him or her more valuable to the organization. Bosses who encourage strategic thinking in their employees find that they are nurturing innovative contributions that enhance the organization's human capital. Managers may challenge employees to find a solution to a problem with which they have had no experience or encourage workers to read articles with which they don't agree.

(7) Integrative Prowess: The act of strategic integration is usually not an easy exercise for the student. A student who is asked, for example, to integrate Porter's Five Force Analysis with generic strategy, frequently troubles over an answer. If this highly conceptual question cannot be answered satisfactorily, the student is stuck. The student won't grasp how the defensive and offensive uses of a particular generic strategy should be designed to protect against external forces that can limit profitability and superior competitiveness.

Integrative thinking about diverse components, levels, and functions serves to permit a relatively seamless strategic process. Strategic thinking inheres at the crux of the organization and environment relationship as strategists assess correspondence between internal strengths and weaknesses to external opportunities and threats. It is through the strategic thinking process that an organization's competitive advantage is initiated and sustained. Strategic thinking integrates the individual as strategist with the organization. Strategic thinking penetrates through corporate, business unit, functional, and operational levels to unify the activities of all parts of the organization. Strategic thinking applied to functional level strategizing serves to integrate across marketing, human resources, operations, and other functional level activities.

(8) The Strategic Hour: Wrote Emerson, 'One of the illusions of life is that the present hour is not the critical, decisive one'. The present hour is the strategic hour-- which is rich with potential. How the student uses the hour, whether the hour is used with care or wasted, is a strategic choice. The student who understands this early has just earned bonus points for richness of potential. That is so for organizations as well. The strategic hour is the hour at hand. As hours pass, days, weeks, and then years, the organization has had the opportunity to engage the strategic thinking process to accomplish brave and brilliant things. Or not...

\section{Future Research Directions}

Threshold Concept Theory invigorates the teaching of the strategic thinking process by supplying a qualitatively elevated platform from which the teaching process and its study may be viewed. Instructors may look upon their course of study with fresh eyes as they seek to ensure that 
students move from troublesome blockages that sustain liminality to a potentially life-changing grasp of the strategic thinking process. The complex task of strategic integration is also given its due as an essential element within the strategic thinking process. Strategic thinking enables the student to gain access to a more meaningful grasp of organization and environment relations, functional level inter-relatedness and connection to the larger organization.

Many, many research questions remain to be answered about threshold concept theory and its applications to strategic thinking and its teaching. Now the discipline of management is opened wide all along its boundaries as the instructor seeks to find yet other such concepts alone and in constellation that obfuscate student ability to have a genuinely strong command of a chosen course of study. For example, in leadership studies, a voluminous management sub-field, concepts such as servant leadership, substitutes for leadership; theories such as expectancy and equity theories have been known to be sources of student perfunctory and fast-dissipating surface-level learning.

Textbook writers, journal editors, and authors themselves might come to give greater attention to essential elements of strategic thinking taught as a process that must be experientially and emotionally engaging, threshold concept theory primed, and meta-cognitively sustainable for the learner.

Student focused research questions for strategic thinking pedagogical research include: What are students doing and not doing that causes some to be stuck indefinitely in a place of liminality? Can students be helped to self- scan for troublesome spots in their own learning? How does the experience of transformation to self-identity as strategist alter students' self-concepts over time and to what effect? How do changes in identity as strategist affect students' career experiences over time?

Instructor focused research questions include: How do instructors help students to take greater responsibility for their own learning? How do instructors reinforce a student's identity as strategist? What are optimal course designs for effective use of experientially-primed material? What is the most effective way to create an immersion experience for the learning of threshold concepts? How do you help students appreciate how they will be able to use strategic tools as frameworks for future strategic thinking?

Transfer of training from classroom to work and life in general is of critical importance to a robust treatment of strategic thinking. What are the key ways to foster truly better quality learning for the student and graduate? Maybe a 10 -point checklist, strategic imagery, a salient horror story and its cautionary reminder....? How does the manager help assure that the organization will use strategic thinking even in the midst of political infighting and other obstacles to adept strategic thinking? What does a life lived strategically look like?

\section{Conclusions/Discussion}

An MBA student who was an undergraduate business major may not necessarily know much about the strategic thinking process itself; a manager may not readily bring to mind strategic frameworks that would have been so useful in competitor analysis... All business students study strategy, but some may not really be strategic thinkers in their work or lives. They may be suspended to varying degrees in a state of strategic liminality because they never really grasped, differentiated, integrated, or applied as they could have.

It is not easy to teach strategic thinking well. Strategic thinking is a conceptual gateway to a way of thinking about organization and environment, and the implications for learning and actual strategic action are significant [13]. Instructors may have made assumptions about the learning process and textbooks may have jumped straight to strategy without first articulating key facets of the strategic thinking process itself.

Strategic thinking is a threshold concept that once understood permits students to see things in new ways. In the ideal, it is a distinct way of thinking in which the shear complexity of a set of circumstances is disciplined through analytic frameworks that search big-picture and systemic, time expansive between past, present, and future, and deeply probing into assumptions, values, and beliefs. The process may appear quick and intuitive, but may alternatively be highly time intensive and drawn out. Some people may think they are 'naturals' as strategists - meaning they did not need any formal training or expert guidance. Yet it is also possible that a strategist may not be truly strategic at all, or may be strategic but not particularly effective as a strategist. The strategist's mental models may be highly underspecified, inappropriate, and/or deficient.

it is devilishly complicated to teach and learn strategic thinking. The big picture must be taken in in a systemic, broad-based, and integrative manner while the thinker spans past, present, and future in an effort to optimize future outcomes. At the same time, the thinker applies varied mental models - for example, political, cultural, and structural lenses in search of clearer vision. Thoughts and emotions are inter-woven through the process even as other co-strategists enter onto the stage with political and other agendas. Reflection assists greatly as the learner seeks to become more effective over time. However it is learned and what ways it may be practiced, strategic thinking is a key supply source for inimitable competitive advantage, innovation, and superior organizational returns. Strategic thinking is a key supply source for individual-level outcomes such as career optimization, individual-organization fit, career-life balance, superior work and life outcomes. The strategic threshold having been crossed into true and deep understanding, the student learner can now become a strategist! 


\section{REFERENCES}

[1] Meyer, J.H.F. \& Land, R. (2005). 'Threshold concepts and troublesome knowledge (2): Epistemological considerations and a conceptual framework for teaching and learning', Higher Education, 49, 373-388.

[2] Manz, C. C. and Neck, C. P. (2014). Mastering Self-Leadership: Empowering Yourself for Personal Excellence, Second Edition, New York: Prentice Hall.

[3] Shanahan, M. and Meyer, J. H. F. (2006). 'The troublesome nature of a threshold concept in Economics', in Meyer, J. H. F. and Land, R. (eds.), Overcoming Barriers to Student Learning: Threshold Concepts and Troublesome Knowledge, (Eds.). New York: Routledge, pp. 100-133.

[4] Weil, S. and Mcguigan, N. (2010). In Meyer, J. H. F., Land, R. and Baillie, C. Threshold Concepts and Transformational Learning, (eds.). Rotterdam: Sense Publishers.

[5] Manz, C. C. and Neck, C. P. (2004). Mastering Self-Leadership: Empowering Yourself for Personal Excellence. Third Edition. Prentice-Hall.

[6] Perkins, D. (1994). 'The many faces of constructivism', Educational Leadership, November, pp. 6-11.

[7] Stevens, D.R. (1997). Strategic Thinking: Success Secrets of Big Business Projects. New York: McGraw-Hill.

[8] Rumelt, R. (2011). Good Strategy/Bad Strategy: The Difference and Why it Matters. New York: Crown Business.

[9] Davey, L. (2014). "Strengthen your strategic thinking muscle", HBR Blog Network, January 21.

[10] Mintzberg, H. (1994). The Rise and Fall of Strategic Planning. New York: The Free Press.

[11] Liedtak, J. (1998). "Strategic thinking: Can it be taught?" Long Range Planning, 31, 1, 120-129.

[12] The Strategic Thinking Coach (2013). 'Strategic thinking versus the "facilitation fluff" of strategic planning', www.strategicthinkingcoach.wordpress.com, accessed February 10, 2014.

[13] Meyer, J. H. F., Land, R. and Smith, J. (2008). Threshold Concepts within the Disciplines, (eds.). Sydney: Sense Publishers.

[14] Perkins, D. (1994). 'The many faces of constructivism', Educational Leadership, November, pp. 6-11.

[15] Cousin, G. (2006). 'Threshold concepts, troublesome knowledge, and emotional capital,' in Meyer, J.H.F. \& Land, R. (2006), (eds.), Overcoming Barriers to Student Learning: Threshold Concepts and Troublesome Knowledge, (Eds.). New York: Routledge.

[16] Mezirow, J. (2000). Learning as Transformation. San Francisco: Jossey-Bass.

[17] Kelly, R. and Crainton P. (2009). 'Transformative Learning: Q\&A with Patricia Crainton, Faculty Focus. Available at: http://www.facultyfocus.com/articles/instructional-design/tra nsformative-learning-qa-with-patricia-crainton/.

[18] Meyer, J. H. F., Land, R. and Baillie, C. (2010). Threshold Concepts and Transformational Learning, (eds.). Rotterdam: Sense Publishers.
[19] O'Sullivan, E. V., Morrell, A., and O'Connor, M. A. (2002). Expanding the Boundaries of Transformative Learning: Essays on Theory and Praxis. New York: Palgrave.

[20] Mauborgne, R, and Kim, W. C (2005). Blue Ocean Strategy: How to Create Uncontested Market Space and Make Competition Irrelevant. Boston: Harvard Business School.

[21] Land, R., Cousin, G., Meyer, J. H. F., and Davies, P. (2006). Implications of threshold concepts for course design and evaluation', in Overcoming Barriers to Student Understanding, Meyer, J.F. H. and Land, R. (Eds.), pp. 195-206.

[22] Ellsworth, E. 1997). Teaching Positions: Different Pedagogies and the Power of Address. New York: Teachers' College Press, 297-324.

[23] Wright, A.L. \& Gilmore, A. (2012). 'Threshold concepts and conceptions: Student learning in introductory management courses', Journal of Management Education, 36, 5, 614-635.

[24] Entwistle, N. (2006). 'Threshold concepts and transformative ways of thinking within research into higher education', In Land, R., Meyer, J.H.F. and Smith, J. Threshold Concepts within the Disciplines, 21-35.

[25] Land, R., Cousin, G., Meyer, J. H. F., and Davies, P. (2006). Implications of threshold concepts for course design and evaluation', in Overcoming Barriers to Student Understanding, Meyer, J.F. H. and Land, R. (Eds.), pp. 195-206.

[26] Conway, M. (2014). 'Strategic thinking: What it is and how to do it', Thinking Futures, thinkingfutures.net, accessed March $15,2014$.

[27] Rein, S. (2010). 'Three keys to improving your strategic thinking', Forbes, November 9.

[28] Meyer, J.H.F. \& Land, R. (2006). Overcoming Barriers to Student Learning: Threshold Concepts and Troublesome Knowledge, (Eds.). New York: Routledge.

[29] Efklides, A. (2006). "Meta cognition, affect, and conceptual difficulty", in Overcoming Barriers to Student Understanding, pp. 48-69.

[30] McGuigan, N. and Kern, T. (2010). 'Leaping over the perceptual threshold in accounting courses: Embracing sustainable assessment and learning design', ATN Assessment Conference, Assessment, Sustainability, Diversity and Innovation, University of Sydney, Sydney, Australia.

[31] Angwin D. (2003). 'Strategy as exploration and interconnection', Chapter 8, in Wilson, D. C. and Cummings, S. C., Images of Strategy. London, Blackwell Publishing.

[32] Cummings, S. and Wilson, D. (2003). Images of Strategy. MA.: Blackwell Publishing.

[33] Krogerus, M. and Tschappeler, R. (2012). The Decision Book: 50 Models for Strategic Thinking, W.W. London: Norton and Company.

[34] Yip, J. and Raelin, J.A. (2011). 'Threshold concepts and modalities for teaching leadership practice', Management Learning, 43(3), 333-354.

[35] Center for Brain Health (2014). 'Do brain games really boast brain power'? www.brainhealth.utdallas.edu, accessed March 


\section{$20,2014$.}

[36] Brain Performance Institute (2014). 'What is brain performance', Brainperformanceinstitute.com, accessed March 13, 2014.

[37] Perkins, D. (1994). 'The many faces of constructivism', Educational Leadership, November, pp. 6-11.

[38] Brown, M. (2003). "Strategic thinking skills--29 clues that you're not dealing with a strategic thinker", Brain zooming.com, accessed March 18, 2013.
[39] Watkins, M. April 20, 2007. 'How to think strategically', Blogs.hbr.org, accessed February 1, 2014.

[40] Shoemaker, P. (2012). '6 habits of true strategic thinkers', Inc. Magazine, March 20.

[41] Burch, H. and Ghosal, S. (2004). A Bias for Action: How Effective Managers Harness Their Willpower, Achieve Results, and Stop Wasting Time. Boston: Harvard Business School Press.

[42] Henry, A.E. (2011). Understanding Strategic Management, second edition, London: Oxford University Press. 